\title{
Strategies for the management of pulmonary arterial hypertension in patients with congenital heart disease
}

\author{
Nathalie Liew ${ }^{1}$, Zoya Rashid ${ }^{1}$ and Robert Tulloh ${ }^{1,2^{*}}$
}

\begin{abstract}
Background: Pulmonary hypertension (PH) is commonly seen in adults who have congenital heart disease (CHD). Therapy is available for pulmonary arterial hypertension (PAH) and has greatly benefitted many patients with PAH related to CHD (PAH-CHD) over the last 15 years, with evidence of improved quality of life and prognosis in those with Eisenmenger syndrome and repaired PAH-CHD.

In this review, we describe the standard management and advanced therapies for $\mathrm{PAH}$, which are available in specialist PH centres around the UK and Ireland, and how these are used in PAH-CHD. Decisions around the choice of therapy are governed by commissioning and available evidence.

Conclusion: We explain the different pathways for action and the variety of medications now at our disposal to help this important group of patients.
\end{abstract}

Keywords: Pulmonary hypertension, Congenital heart disease, Sildenafil, Tadalafil, Bosentan, Ambrisentan, Macitentan, Epoprostenol, Iloprost, Treprostinil

\section{Background}

Eisenmenger syndrome (ES) is a multisystem disorder characterised by severely elevated pulmonary arterial pressures and pulmonary vascular resistance leading to cyanosis due to reversal of blood flow from a previous left to right shunt. It represents an advanced form of PAH associated with CHD $[1,2]$ that can lead to multiorgan involvement and systemic complications related to the underlying disease, the $\mathrm{PH}$ and also the chronic hypoxaemia. Despite ongoing advances in care, approximately $10 \%$ of patients with CHD develop PAH. PAHCHD is now one of the most common causes of PAH, along with idiopathic PAH and connective tissue diseaserelated PAH. The present clinical subclassification of PAHCHD is now aligned with the 5th and 6th World Symposia

\footnotetext{
* Correspondence: Robert.Tulloh@bristol.ac.uk

'Bristol Heart Institute and Bristol Medical School, Bristol, UK

${ }^{2}$ Department of Congenital Heart Disease Bristol BS2 8HW, UK
}

on PH (2013 and 2018) held in Nice, France [3, 4]. We now see at least four individual subgroups of PAH-CHD patients with their distinct phenotypes: A) Eisenmenger syndrome; B) Left-to-right shunts with mild-moderate $\mathrm{PAH}$; C) $\mathrm{PAH}$ with small/coincidental defects; and D) Postoperative PAH.

Previous papers in this supplement, have detailed the classification, pathophysiology, investigation and standard treatment for PAH-CHD. Prior to 1995, the standard therapies for PAH-CHD were limited and mainly supportive. Standard regimens included calcium channel blockers (nowadays not recommended for PAH-CHD), oral anticoagulation, diuretics and oxygen supplementation, leading to eventual lung or heart-lung transplant. However, studies have shown little improvement in survival rates in most people under these standard therapies, and neither oxygen nor anticoagulation is routinely used in PAH-CHD. With better understanding of the biology of $\mathrm{PAH}$, three groups of pulmonary vasodilators

(c) The Author(s). 2020 Open Access This article is licensed under a Creative Commons Attribution 4.0 International License, which permits use, sharing, adaptation, distribution and reproduction in any medium or format, as long as you give appropriate credit to the original author(s) and the source, provide a link to the Creative Commons licence, and indicate if changes were made. The images or other third party material in this article are included in the article's Creative Commons licence, unless indicated otherwise in a credit line to the material. If material is not included in the article's Creative Commons licence and your intended use is not permitted by statutory regulation or exceeds the permitted use, you will need to obtain permission directly from the copyright holder. To view a copy of this licence, visit http://creativecommons.org/licenses/by/4.0/ The Creative Commons Public Domain Dedication waiver (http://creativecommons.org/publicdomain/zero/1.0/) applies to the data made available in this article, unless otherwise stated in a credit line to the data. 
have emerged as therapies for PAH. These include phosphodiesterase type 5 inhibitors (and soluble guanylate cyclase stimulators), endothelin receptor antagonists and prostacyclin analogues (or receptor agonists). Despite a significant improvement in functional capacity, morbidity and mortality in some PAH-CHD groups (namely groups $\mathrm{A}$ and $\mathrm{D}$ ), the long-term effect on morbidity, mortality, as well health service utilisation remains somewhat uncertain.

This review provides a summary of key data on emerging treatments and the suitability of different classes of drugs and interventions for PAH-CHD patients. Standard therapy is provided in another paper in this supplement and will not be included here.

\section{Advanced PAH-specific therapy}

In PAH-CHD, left-right shunting causes an increase in pulmonary blood flow, exerting shear stress on the pulmonary endothelium and causing histopathological and pathobiological changes that are similar to those observed in other forms of PAH [2]. Endothelial dysfunction of the pulmonary vasculature plays a key role in the progression of $\mathrm{PAH}$ and is characterised by impaired synthesis of vasodilatory nitric oxide $(\mathrm{NO})$ and prostacyclin, overproduction of vasoconstricting thromboxane A2 and endothelin. These observations have underpinned three therapeutic target pathways in $\mathrm{PAH}$, which will be further evaluated in this review.

\section{Phosphodiesterase type $\mathbf{5}$ inhibitors}

Sildenafil is a phosphodiesterase type 5 inhibitor (PDE5i), which is widely used due to ease of use and low cost, that increases the level of cyclic guanosine monophosphate (cGMP) in the body [5]. The accumulation of cGMP then leads to a series of cellular changes that concludes with a decrease in intracellular calcium levels, improved right ventricular function and reduced vascular smooth muscle contraction [6]. In general practice the most frequent of the adverse reactions to the treatment are in order of frequency, vomiting, headache, bronchitis, pyrexia, pharyngitis, cough, diarrhoea and nasopharyngitis (nasal "stuffiness").

There is now good evidence for benefit in ES. Several studies have shown improvement in WHO functional class, and almost all of these have shown an increase in 6-min walk distance (6MWD) [7-13]. In addition, tadalafil, a longer acting PDE5i has been shown to improve WHO functional class, increase 6MWD and reduce PVR in this same group [14].

\section{Soluble guanylate cyclase stimulator Riociguat}

A novel class of drugs targeting the NO pathway are the soluble guanylate cyclase (sGC) stimulators, with riociguat being the first to be approved. Riociguat facilitates the binding of sGC to $\mathrm{NO}$ by stabilising the NO-sGC bond. This compound acts independently from endogenous NO production and is able to increase intracellular cGMP levels by direct stimulation of sGC, provided the haem group of $\mathrm{sGC}$ remains active.

The PAH sGC-stimulator Trial-1 (PATENT-1) was a 12-week long, randomised, double-blind, placebocontrolled phase III clinical trial which enrolled a subgroup of 35 patients with PAH-CHD following cardiac surgery $[15,16]$. Post hoc analysis showed considerable improvement $(>10 \%)$ in 6MWD and pulmonary vascular resistance (PVR) from baseline in patients who received riociguat (either low-dose $1.5 \mathrm{mg}$ or high dose $2.5 \mathrm{mg}$ three times daily). Other outcomes observed in this trial included an improvement in subjects' exercise capacity, haemodynamics, $\mathrm{N}$-terminal pro brain natriuretic peptide (NT-proBNP) levels and WHO functional class. A second post hoc analysis was carried out in PATENT-2, an open-label long term extension of PATENT-1 where patients were followed up for a further 2 years [16]. In PATENT-2, 33 of the 35 patients with PAH-CHD enrolled in PATENT-1 were continued on long-term riociguat (2.5 mg three times daily) with the aim to assess safety and tolerability of the drug. Improvements in 6MWD in the treatment group of PATENT-1 were sustained at 2 years of PATENT-2 (an additional 18.7\% improvement in the former $2.5 \mathrm{mg}$ riociguat group). With regards to adverse effects, the incidence of syncope and hypotension (side effects that have been reported as frequent with riociguat) were relatively low in CHD patients.

At present, most studies on advanced PAH-specific therapies (including PDE5i and ERAs) only include closed defects or those specifically with ES and no studies have looked at those with persisting left to right shunts or those with small defects, making it difficult to draw comparisons. Several randomised controlled trials have included PAH-CHD with closed defects and have studied PAH therapies in ES, but there are very few data about treatments in left to right shunts and those patients with small defects. Riociguat has been approved both for the treatment of PAH and inoperable or persistent (after surgery) chronic thromboembolic pulmonary hypertension (CTEPH) but is mainly used in PAH-CHD for those who do not tolerate PDE5i as an alternative therapy [17].

\section{Endothelin pathway and Endothelin receptor antagonists (ERA)}

Endothelin 1 (ET-1) is a vasoactive peptide that plays a key role in the cardiovascular system. It works by exerting vasoconstrictor and mitogenic effects by binding to two distinct G-protein receptor sub-types in the pulmonary vascular smooth muscle, including ET-A and ET-B [18]. Plasma ET-1 concentrations in the PAH- 
CHD group were found to be significantly higher in the superior and inferior vena cava, right atrium, right ventricle, pulmonary artery and pulmonary vein.

Bosentan is an oral, dual ET-A and ET-B endothelin receptor antagonist (ERA) and the first molecule from this class to be synthesised. To date, it is the most well-studied drug used in the treatment of ES. Approved in 2001, joint guidelines from the European Society of Cardiology and European Respiratory Society recommend that bosentan therapy is initiated in ES [19]. The Bosentan Randomised Trial of Endothelin Antagonist THErapy-5 (BREATHE-5) study was the first trial designed as a multicentre, randomised, double-blind, placebo-controlled study evaluating the effect of bosentan in patients with ES [20]. Fifty-four patients $>12$ years of age with WHO functional class III ES were enrolled; 37 received bosentan and 17 received placebo over 16 weeks. The 6MWD improved by $13 \%$ in the bosentan group and decreased by $3 \%$ in the placebo group. Similar favourable results have been reported in other controlled studies evaluating the effects of bosentan in PAH-CHD [21]. Furthermore, improvements in exercise capacity were maintained in the same cohort of patients following 24 additional weeks in an open-label extension of BREATHE- 5 with the former placebo group experiencing an increase in 6MWD by $8.3 \%$ from baseline following bosentan therapy. With regards to adverse effects, peripheral oedema was the most common side effect occurring in $19 \%$ of patients on bosentan versus $6 \%$ on placebo. Other less common side effects reported were headache, palpitations, dizziness, and chest pain. One patient had to discontinue because of elevated liver enzymes $>5$ times the upper limit of normal. This is consistent with other studies which showed that approximately $10 \%$ of patients had increases in hepatic aminotransferases and this was found to be dose dependent and reversible after dose reduction or withdrawal. For these reasons, patients on bosentan should have their liver function monitored monthly.

\section{Other ERA}

Macitentan is the newest ERA studied for the treatment of PAH. Like bosentan, macitentan acts on both ET-A and ET-B receptors [22]. Macitentan achieves a high affinity for the lipophilic milieu, with a 40- and 2000fold increased affinity for the lipid phase versus bosentan and ambrisentan (another more ET-A selective ERA), respectively, and has superior pre-clinical in vivo efficacy [23]. Furthermore, the duration of action of macitentan was approximately $40 \mathrm{~h}$ at its maximal effective dose, double that of bosentan [24].

SERAPHIN (Study with an Endothelin Receptor Antagonist in Pulmonary Arterial Hypertension to Improve Clinical Outcome) was a multicentre, double-blind, randomised controlled trial assessing the effect of macitentan on morbidity and/or mortality in PAH patients [25]. The primary endpoint was the time from initiation of treatment. This was either placebo, $3 \mathrm{mg}$ of macitentan, or 10 mg of macitentan to time of first occurrence of a composite endpoint of worsening of $\mathrm{PAH}$, initiation of intravenous or subcutaneous prostanoids, lung transplantation, atrial septostomy, or death. The SERAPHIN population included 62 PAH-CHD patients. Analysis overall showed a significant improvement in the time to clinical worsening and 6MWD in those with combination therapy [26].

The Macitentan in Eisenmenger Syndrome to Restore Exercise Capacity (MAESTRO) global trial enrolled 226 ES patients. Initial analysis showed that there was no significant improvement in the primary endpoint of exercise capacity (6MWD) but of note there was a decrease in this endpoint in the placebo group. There was however significant decrease in NT-pro-BNP levels (by $20 \%$ ), reduction in PVR (by 13\%), and good tolerability of the drug in the haemodynamic invasive substudy, advocating for further studies to evaluate the role of macitentan in the management of ES and other forms of $\mathrm{PAH}-\mathrm{CHD}$ [27]. Prospective non-randomised data are providing promising signals on the safety and efficacy for macitentan in PAH-CHD $[28,29]$. Although the data is not fully convincing, Macitentan remains a useful therapy for its other benefits, being once a day usage and reduced drug-drug interactions. The combination of macitentan and tadalafil (Optima study) showed significant improvement in outcomes, with a reduction in PVR of $47 \%$ along with similar improvements in NT-proBNP and 6MWD [30].

\section{Prostacyclin pathway}

Predominantly produced by endothelial cells, prostacyclin originates from the eicosanoid family of mediators, which also include prostaglandins, leukotrienes, and thromboxanes. Prostacyclin is the most potent endogenous inhibitor of platelet aggregation with cytoprotective and antiproliferative properties [31]. It works by activating cell surface receptors and cytosolic peroxisome proliferator-activated receptors. For prostacyclin, the preferred cell surface receptors are the IP receptors, which originate from G protein-coupled receptors. IP receptors are coupled to the activation of adenylate cyclase, allowing the conversion of adenosine triphosphate to a second messenger, cyclic adenosine monophosphate (cAMP). Through the activation of the cAMP-dependent protein kinases, this powerful messenger exerts different effects on various tissues, including vasorelaxation in vascular smooth muscle and inhibition of thrombosis, by acting on platelets.

In $\mathrm{PAH}$, we see an imbalance between vasodilators, such as prostacyclin, which are lacking, and vasoconstrictors, which are in excess. Prostacyclin and other related drug analogues have undeniably revolutionised 
the treatment of PAH since their discovery in the 1970s, but their use in PAH-CHD has been limited by adverse effects and, in the case of intravenous prostacyclins, the need for an indwelling central venous line, with the associated risk of thrombosis and paradoxical embolism. For this reason, drugs acting on the prostacyclin pathway are restricted to $\mathrm{PAH}$ patients in WHO functional class III or IV, with rapid disease progression and/or lack of response to oral therapies. Therapies targeting the prostacyclin pathway have been available for many years, starting with epoprostenol in PAH-CHD [32-34].

Iloprost is a stable analogue of prostacyclin that can be administered intravenously or by inhalation, avoiding many of the systemic side effects associated with intravenous administration. Aerosolisation of prostacyclin has been shown to cause selective but short-lived pulmonary vasodilatation, increased cardiac output, and subsequently improve oxygenation in patients with $\mathrm{PAH}$ [35]. Like prostacyclin, iloprost has vasodilatory and antiplatelet effects, but has a longer plasma half-life of 20 to $30 \mathrm{~min}$; moreover, its improved solubility in saline enables administration by intermittent nebulisation [36-38]. Designed to combine the beneficial long-term effects of continuous infusion of intravenous prostacyclin with the benefits of inhaled nitric oxide, iloprost has been classed as a promising agent for patients with $\mathrm{PAH}$, but strong data are lacking. Skoro-Sajer et al. reported on the use of subcutaneous treprostinil, avoiding the need for indwelling central venous lines in a cohort of 32 WHO functional class III or class IV patients with ES (see Table 1) [44]. Patients had demonstrated lack of response to bosentan or had not yet started this ERA. WHO functional class improved significantly as did BNP levels and PVR.

Selexipag is a new oral IP receptor agonist, which appears to be effective in $\mathrm{PAH}$, including patients with repaired CHD [47, 48]. The randomised controlled GRIP HON study included 110 patients with corrected CHD [49]. The composite primary outcome of mortality and morbidity was significantly improved by selexipag therapy and it was well tolerated in this subgroup [50].

\section{Determinants of successful treatment}

The aims of PAH therapies are well described in the European Guidelines [19] with a wish to move patients from high to lower risk. A combination of two agents, such as a PDE5i and an ERA, appears more likely to reduce the mortality, aiming to shift patients towards the "green" low risk zone for the clinical indices. At the current time, most clinicians will opt for a combination of PDE5i and ERA upfront or in rapid succession in order to achieve treatment goals as fast as is reasonable, within current commissioning and reimbursement guidelines.

\section{Assessing suitability of different therapies for groups of PAH-CHD}

With recent successes in clinical trials, the treatment for PAH-CHD patients has evolved progressively. Over the last decade, advanced PAH-specific therapy has become widely adopted in the treatment of PAH-CHD, especially ES, and for those with closed defects. Risk stratification remains a pivotal part of assessing suitability of treatment, response and timing of intervention, as well as disease progression and prognosis [51] . The WHO functional classification, despite its interobserver variability, remains one of the most widely used predictors of survival at diagnosis and subsequent follow-up. Other important predictors include 6MWD, peak oxygen uptake, markers of right ventricular (RV) dysfunction, haemodynamics, biomarkers and imaging.

Clinical assessment remains a pivotal part of managing these challenging cohorts as it provides valuable information in determining disease severity, improvement, stability, or deterioration. Elementary parts of the history should gauge important symptoms such as chest pain, changes in exercise tolerance, arrhythmia, syncope, and haemoptysis. Other important physical signs to look out for are the presence and severity of cyanosis, jugular venous pressure, oedema, ascites, and systemic blood pressure. Echocardiography is an important follow-up tool, as RV function is one of the key determinants of exercise capacity and prognosis in patients with PAH and there are now well described predictors of outcome [52].

\section{Group A - Eisenmenger syndrome}

Due to the complexity and severity of ES, usually augmented by systemic complications and comorbidities, determination of best treatment strategy remains a huge challenge. The BREATHE- 5 trial was one of the first and largest trials of therapy in PAH-CHD. It showed that treatment with bosentan was safe in this group of patients [20]. However, no head-to-head studies have ever been performed to decide which therapy is the most efficacious in PAH-CHD. Most studies have been small observational studies using tadalafil and sildenafil $[12,14]$.

In a retrospective study, a cohort of 79 ES patients treated in a single institution for a period of up to 8.9 years was presented [53]. PAH therapies consisting of bosentan, sildenafil, sitaxentan, ambrisentan, tadalafil and inhaled iloprost as monotherapy, dual therapy, and triple therapy. It is noteworthy that due to the progressive nature of ES, 18 patients (23\%) required up titration of therapy or introduction of dual or triple therapy after a median period of 2.5 years. A further observation from this study was that oxygen saturation during exercise improved with $\mathrm{PAH}$ therapy, indicating possible improvement in tissue oxygen delivery, which is likely to result in better exercise capacity. This study suggests that PAH 
Table 1 Published studies of therapies in ES (from [39])

\begin{tabular}{|c|c|c|c|c|c|c|c|}
\hline Class & First author & Year & Drug & $\mathbf{N}$ & $\begin{array}{l}\text { FC \% change } \\
\text { II/III/IV } \\
\text { or mean }\end{array}$ & RCT & Main findings \\
\hline \multirow[t]{5}{*}{ ERA } & Galiè [20] & 2006 & Bosentan & 54 & $0 / 100 / 0$ & Yes & $\downarrow \mathrm{PVRi}, \downarrow \mathrm{mPAP}, \uparrow 6 \mathrm{MWD}$ \\
\hline & Zuckerman [40] & 2011 & Ambrisentan & 17 & NR & No & $\uparrow 6 \mathrm{MWD}$ \\
\hline & Blok [28] & 2017 & Macitentan & 40 & $52 / 48 / 0$ & No & $\downarrow F C, \downarrow N T-p r o B N P, \leftrightarrow 6 \mathrm{MWD}$ \\
\hline & Herbert [29] & 2017 & Macitentan & 15 & NR & No & $\uparrow 6 \mathrm{MWD}, \uparrow \mathrm{SaO}_{2}$ \\
\hline & Galie [41] & 2017 & Macitentan & 226 & $60 / 40 / 0$ & Yes & $\leftrightarrow 6 \mathrm{MWD}, \downarrow N \mathrm{NT}$-proBNP, $\downarrow$ PVRi \\
\hline \multirow[t]{7}{*}{ PDE5i } & Mukhopadhyay [7] & 2006 & Sildenafil & 16 & $69 / 31 / 0$ & No & $\uparrow 6 \mathrm{MWD}, \uparrow \mathrm{SaO}_{2}, \downarrow \mathrm{mPAP}, \downarrow \mathrm{PVR}$ \\
\hline & Chau [42] & 2007 & Sildenafil & 7 & $3.3 \pm 0.7$ & No & $\downarrow F C, \uparrow \mathrm{SaO}_{2}, \downarrow \mathrm{mPAP}, \downarrow \mathrm{PVR}$ \\
\hline & Garg [10] & 2007 & Sildenafil & 21 & $46 / 54 / 0$ & No & $\downarrow F C, \uparrow 6 \mathrm{MWD}, \uparrow \mathrm{SaO}_{2}, \downarrow \mathrm{mPAP}, \downarrow$ PVRi \\
\hline & Tay [11] & 2011 & Sildenafil & 12 & 0/100/0 & No & $\downarrow F C, \uparrow 6 \mathrm{MWD}, \uparrow \mathrm{HRQOL}$ \\
\hline & Zhang [12] & 2011 & Sildenafil & 84 & $52 / 39 / 8$ & No & $\uparrow 6 \mathrm{MWD}, \uparrow \mathrm{SaO}_{2}, \downarrow \mathrm{mPAP}, \downarrow \mathrm{PVRi}$ \\
\hline & Mukhopadhyay [14] & 2011 & Tadalafil & 28 & $79 / 21 / 0$ & Yes & $\downarrow F C, \uparrow 6 \mathrm{MWD}, \downarrow P V R$ \\
\hline & Sun [13] & 2013 & Sildenafil & 29 & NR & No & $\downarrow F C, \uparrow 6 \mathrm{MWD}, \downarrow P V R$ \\
\hline \multirow[t]{7}{*}{ Prostanoid } & Rosenzweig [32] & 1999 & Epoprostenol (intravenous) & 20 & $15 / 50 / 35$ & No & $\downarrow \mathrm{mPAP}, \uparrow \mathrm{Cl}, \downarrow \mathrm{PVRi}, \uparrow S \mathrm{O}_{2}$ \\
\hline & Fernandes [33] & 2003 & Epoprostenol (intravenous) & 8 & 0/25/75 & No & $\uparrow 6 \mathrm{MWD}$ \\
\hline & Thomas [43] & 2013 & $\begin{array}{l}\text { Epoprostenol (intravenous) } \\
\text { \& Treprostinil (subcutaneous) }\end{array}$ & 9 & $12 / 88 / 0$ & No & $\downarrow \mathrm{mPAP}, \uparrow \mathrm{SVO}_{2}$ \\
\hline & Skoro-Sajer [44] & 2018 & Treprostinil (subcutaneous) & 22 & $0 / 47 / 53$ & No & $\downarrow F C, \downarrow P V R, \downarrow N T-p r o B N P, \uparrow 6 \mathrm{MWD}$ \\
\hline & Yang [36] & 2012 & Iloprost (nebulised) & 12 & $0 / 75 / 25$ & No & $\downarrow F C, \uparrow 6 \mathrm{MWD}, \uparrow \mathrm{SaO}_{2}$ \\
\hline & Cha [37] & 2013 & Iloprost (nebulised) & 13 & $0 / 69 / 31$ & No & $\downarrow F C, \uparrow 6 \mathrm{MWD}, \uparrow H \mathrm{HQOL}$ \\
\hline & Chon [38] & 2017 & Iloprost (nebulised) & 11 & $0 / 64 / 36$ & No & $\downarrow F C, \downarrow m P A P, \downarrow P V R, \uparrow S a O_{2}, \uparrow 6 \mathrm{MWD}$ \\
\hline \multirow[t]{3}{*}{ Combination } & Iversen [45] & 2010 & Bosentan +/- Sildenafil & 21 & $43 / 48 / 5$ & Yes & $\leftrightarrow 6 \mathrm{MWD}, \uparrow \mathrm{SaO}_{2}$ \\
\hline & D'Alto [46] & 2012 & Bosentan \& Sildenafil & 32 & $2.9 \pm 0.3$ & No & $\begin{array}{l}\downarrow F C, \uparrow 6 \mathrm{MWD}, \downarrow \mathrm{mPAP}, \downarrow \mathrm{PVR}, \\
\downarrow N T-\text { proBNP }\end{array}$ \\
\hline & Sitbon [30] & 2020 & Macitentan \& Tadalafil & 46 & 63\% improved FC & No & $\downarrow P \vee R, \downarrow N T-$ proBNP \\
\hline
\end{tabular}

Abbreviations and legend. Cl: Cardiac index, FC: Functional class, HRQoL: Health related quality of life, mPAP: mean pulmonary artery pressure, NT-proBNP: N terminal pro-Brain natriuretic peptide, PVR(i): Pulmonary vascular resistance (indexed), $\mathrm{SaO}_{2}$ : peripheral oxygen saturation, $6 \mathrm{MWD}$ : 6 min walk distance, SvO $\mathrm{O}_{2}$ : mixed venous oxygen saturation $\uparrow:$ Increased, $\downarrow$ :Decreased, $\leftrightarrow$ : No change

Reproduced and updated from Condliffe R, Clift P, Dimopoulos K, Tulloh RMR. Management dilemmas in pulmonary arterial hypertension associated with congenital heart disease. Pulmonary Circulation 8(3), pp. 1-12. Copyright $\odot 2018$ by the Authors. Reprinted by permission of SAGE Publications, Ltd.

therapies can have a long-standing beneficial effect in patients with ES with simple defects and may improve survival [54].

Expert centres may also use PAH-therapies in ES patients with complex anatomy and segmental pulmonary hypertension [55]. The use of advanced PAH-specific therapy has, however, not been formally assessed in ES patients with univentricular circulation (e.g. double inlet left ventricle) as many RCTs have excluded these complex patients due to difficulties in estimating PVR. However, there is evidence for use in complex diseases, but more detailed studies are needed [56-59]. Theoretically, using advanced therapy to increase pulmonary blood flow (Qp) may result in a reduction in peripheral cyanosis and improve oxygen delivery. However, caution must be exercised as significant increase in Qp can lead to volume overload in the single ventricle supporting both the systemic and pulmonary circulation and may precipitate ventricular dysfunction. As data are lacking, no strict recommendations can be put forward and decisions should be made on an empiric basis.

\section{Group B - left to right shunts}

In this group, $\mathrm{PH}$ is less severe than in ES patients and is associated with left-to-right shunt [60]. Cardiac catheterisation is used to decide which patients may be referred for surgical or interventional shunt closure. No prospective data is available on the use of invasive pulmonary vasoreactivity in determining outcome or suitability for repair [61]. In the case of correctable $\mathrm{CHD}$, timely surgical repair is paramount in preventing 
pulmonary vascular disease, as early changes in the pulmonary vascular bed are likely to be reversible following shunt repair. In general, patients with prevalent systemic-to-pulmonary shunts and normal PVR can safely undergo shunt closure, whereas when PVR is mildly raised, expert opinion should be sought. European PH guidelines [51] recommend a PVR index (PVRi) of $<4$ WU.m $^{2}$ (PVR $<2.3 \mathrm{WU}$ ) as the haemodynamic upper limit for operability in patients with atrial septal defect (ASD) or ventricular septal defect (VSD), thus discouraging shunt closure in cases of severe PAH with some caution for those with PVRi of between 4 and 8 WU. ${ }^{2}$. The use of PVRi is not clearly advantageous. With the increase in population body weights, significant numbers of people have an increase in body mass index, but this may be due to additional body fat, rather than increased size of the pulmonary or systemic circuit. At present, there are no established markers of reversibility, nor evidence-based algorithms to guide assessment for operability in this group of patients and decisions should be made on a case-by-case basis in tertiary centres with expertise in PAH-CHD. While some atrial level shunts serve as a potential relief valve in patients with severe $\mathrm{PH}$, we await future results on the optimal fenestration size.

Considerations for shunt closure should also include, beyond PVR, type of defect, the PVR:systemic vascular resistance (SVR) ratio, as well as the systemic to pulmonary flow (Qp:Qs) ratio [62].

\section{Group C - PAH with coincidental CHD (small defects)}

In patients with $\mathrm{PAH}$ with small defects (typically VSD $<1 \mathrm{~cm}$ and/or ASD $<2 \mathrm{~cm}$ of effective diameter assessed by echocardiography), the clinical picture has been described to be very similar to patients with idiopathic PAH (IPAH). In most recent large trials of PAH therapies, patients are on combination medication.

\section{Group D - post-operative PAH}

Patients with postoperative PAH are also pathophysiologically very similar to patients with IPAH. Therefore, these patients should be treated according to current $\mathrm{PAH}$ guidelines [51]. In a retrospective study on the different clinical groups of PAH-CHD patients, the lowest survival was observed in patients with small/coincidental defects and post defect repair [63]. The 15-year survival of groups with small defects (66\%) was even worse when compared to patients with ES (87\%) (Table 2), which suggests that the lack of a 'blow off valve' to relieve right ventricular strain worsens prognosis in such patients.

This material has not been reviewed prior to release; therefore the European Respiratory Society may not be responsible for any errors, omissions or inaccuracies, or for any consequences arising there from, in the content. Reproduced with permission of the $\odot$ ESC \& ERS 2019. European Respiratory Journal Oct 2015, 46 (4) 903-975; https://doi.org/10.1183/13993003.01032-2015

\section{Conclusion}

ES or one of the other forms of PAH-CHD, represents a severe condition that is associated with considerable morbidity and limited life expectancy. More children born with CHD are advancing into adulthood as a result of advancements in medical care. As such, there is an urgent need for optimisation of care in this population of adults, who are susceptible to disease-related complications.

Current available PAH-specific treatments include a variety of agents covering different mechanisms of action: PDE5i's, sGC stimulators, ERAs, prostacyclin analogues and prostacyclin receptor agonists. This review found that bosentan, riociguat, epoprostenol and sildenafil were all capable of improving functional capacity and haemodynamic parameters in patients with $\mathrm{PAH}-$ CHD but whether this corresponds with improved mortality remains to be seen, with only epoprostenol shown to have better survival rates. A combination therapy of ERA and PDE5i can be considered in order to improve outcomes in the former group of patients.

It is pivotal to recognise the unique pharmacological characteristics of drugs within each class and the specific evidence supporting the use of each treatment. Continued research to quantify the value of earlier treatment and combined regimens of targeted $\mathrm{PAH}$ therapies are likely to complement current insights and potentially revolutionise the treatment of PAH-CHD.

Table 2 Criteria for closing cardiac shunts in PAH-CHD (from [51])

\begin{tabular}{|c|c|c|c|c|}
\hline \multicolumn{2}{|c|}{ Pulmonary vascular resistance } & \multirow{2}{*}{$\begin{array}{l}\text { Recommendations } \\
\text { Correctable* }\end{array}$} & \multirow{2}{*}{$\begin{array}{l}\text { Class of } \\
\text { evidence }\end{array}$} & \multirow{2}{*}{$\begin{array}{l}\text { Level of } \\
\text { evidence }\end{array}$} \\
\hline $\begin{array}{l}\text { PVRi } \\
\left(\text { WU.m }{ }^{2}\right)\end{array}$ & $\begin{array}{l}\text { PVR } \\
\text { (WU) } \\
\end{array}$ & & & \\
\hline$<4$ & $<2.3$ & Yes & Ila & C \\
\hline$>8$ & $>4.6$ & No & \|la & C \\
\hline $4-8$ & $2.3-4.6$ & $\begin{array}{l}\text { Individual patient } \\
\text { evaluation in } \\
\text { tertiary centres }\end{array}$ & Ila & C \\
\hline
\end{tabular}




\section{Abbreviations}

ASD: Atrial septal defect; CAMP: Cyclic adenosine monophosphate; CGMP: cyclic guanosine monophosphate; CHD: Congenital Heart Disease; CTEPH: Chronic thromboembolic pulmonary hypertension; ERA: Endothelin receptor antagonist; ES: Eisenmenger syndrome; ET-A or ET-B: Endothelin receptor type A or type B; NO: Nitric oxide; NT-pro-BNP: N Terminal pro Brain type natriuretic peptide; PAH: Pulmonary Arterial Hypertension; PDA: Persistent arterial duct; PDE5i: Phosphodiesterase type 5 inhibitor; PVR(i): Pulmonary vascular resistance (indexed); Qp: Pulmonary blood flow; Qs: Systemic blood flow; sGC: Soluble Guanylate cyclase stimulator; SVR: Systemic vascular resistance; VSD: Ventricular septal defect; WHO: World Health Organisation; 6MWD: Six-minute walk distance

\section{Acknowledgements}

Not applicable.

\section{About this supplement}

This article has been published as part of Journal of Congenital Cardiology Volume 4 Supplement 1 2020: Unmet needs in Pulmonary Hypertension associated with Adult Congenital Heart Disease (ACHD-PH). The full contents of the supplement are available at https://jcongenitalcardiology. biomedcentral.com/articles/supplements/volume-4-supplement-1

\section{Authors' contributions}

$\mathrm{NL}, \mathrm{ZR}$ and RT contributed to the design and writing of the article and all authors approved the final manuscript.

\section{Authors' information}

Not applicable.

\section{Funding}

Professor Tulloh is supported by the NIHR Biomedical Centre at the University Hospitals Bristol and Weston NHS Foundation Trust and the University of Bristol.

Medical writing support was provided by nspm Itd, Meggen, Switzerland. The manuscript was funded by a Medical and Educational Goods and Services (MEGS) grant and Actelion Pharmaceuticals UK Limited (who had no influence on manuscript writing).

\section{Availability of data and materials}

No original data was used in this review article.

\section{Ethics approval and consent to participate}

Not applicable.

\section{Consent for publication}

Not applicable.

\section{Competing interests}

Professor Robert Tulloh has received unrestricted educational, travel or research grants from Bayer, Pfizer, Actelion, Janssen and GSK. Zoya Rashid has received a travel grant from Actelion pharmaceuticals.

\section{Received: 12 November 2020 Accepted: 12 November 2020} Published: 16 December 2020

\section{References}

1. Wood $\mathrm{P}$. The eisenmenger syndrome or pulmonary hypertension with reversed central shunt. Br Med J. 1958:2:701-9.

2. Bradford R, Tulloh R. Diagnosis and Management of Pulmonary hypertension in adult congenital heart disease. Br J Cardiac Nurs. 2008;3: $138-45$.

3. Galie N, Simonneau G. The fifth world symposium on pulmonary hypertension. J Am Coll Cardiol. 2013;62(25 Suppl):D1-3.

4. Galie N, McLaughlin W, Rubin LJ, Simonneau G. An overview of the 6th World Symposium on Pulmonary Hypertension. Eur Respir J. 2019;53:1.

5. Hemnes AR, Champion HC. Sildenafil, a PDE5 inhibitor, in the treatment of pulmonary hypertension. Expert Rev Cardiovasc Ther. 2006;4(3):293-300.

6. Lucas KA, Pitari GM, Kazerounian S, Ruiz-Stewart I, Park J, Schulz S, et al. Guanylyl cyclases and signaling by cyclic GMP. Pharmacol Rev. 2000;52(3): 375-414.
7. Mukhopadhyay S, Sharma M, Ramakrishnan S, Yusuf J, Gupta MD, Bhamri N, et al. Phosphodiesterase-5 inhibitor in Eisenmenger syndrome: a preliminary observational study. Circulation. 2006;114(17):1807-10.

8. Singh TP, Rohit M, Grover A, Malhotra S, Vijayvergiya R. A randomized placebo-controlled, double-blind, crossover study to evaluate the efficacy of oral sildenafil therapy in severe pulmonary artery hypertension. Am Heart J. 2006;151(4):851 e1-5.

9. Chau EM, Fan KY, Chow WH. Effects of chronic sildenafil in patients with Eisenmenger syndrome versus idiopathic pulmonary arterial hypertension. Int J Cardiol. 2007;120(3):301-5.

10. Garg N, Sharma MK, Sinha N. Role of oral sildenafil in severe pulmonary arterial hypertension: clinical efficacy and dose response relationship. Int $J$ Cardiol. 2007;120(3):306-13.

11. Tay EL, Papaphylactou M, Diller GP, Alonso-Gonzalez R, Inuzuka R, Giannakoulas G, et al. Quality of life and functional capacity can be improved in patients with Eisenmenger syndrome with oral sildenafil therapy. Int J Cardiol. 2011:149(3):372-6.

12. Zhang $Z N$, Jiang $X$, Zhang $R$, Li XL, Wu BX, Zhao QH, et al. Oral sildenafil treatment for Eisenmenger syndrome: a prospective, open-label, multicentre study. Heart. 2011;97(22):1876-81.

13. Sun YJ, Yang T, Zeng WJ, Gu Q, Ni XH, Zhao ZH, et al. Impact of sildenafil on survival of patients with Eisenmenger syndrome. J Clin Pharmacol. 2013; 53(6):611-8.

14. Mukhopadhyay S, Nathani S, Yusuf J, Shrimal D, Tyagi S. Clinical efficacy of phosphodiesterase-5 inhibitor tadalafil in Eisenmenger syndrome--a randomized, placebo-controlled, double-blind crossover study. Congenit Heart Dis. 2011;6(5):424-31.

15. Ghofrani HA, Galie N, Grimminger F, Grunig E, Humbert M, Jing ZC, et al. Riociguat for the treatment of pulmonary arterial hypertension. $N$ Engl J Med. 2013;369(4):330-40.

16. Rosenkranz S, Ghofrani HA, Beghetti M, Ivy D, Frey R, Fritsch A, et al. Riociguat for pulmonary arterial hypertension associated with congenital heart disease. Heart. 2015;101(22):1792-9.

17. Ghofrani HA, Humbert M, Langleben D, Schermuly R, Stasch JP, Wilkins MR, et al. Riociguat: mode of action and clinical development in pulmonary hypertension. Chest. 2017;151(2):468-80.

18. Yoshibayashi M, Nishioka K, Nakao K, Saito Y, Matsumura M, Ueda T, et al. Plasma endothelin concentrations in patients with pulmonary hypertension associated with congenital heart defects. Evidence for increased production of endothelin in pulmonary circulation. Circulation. 1991;84(6):2280-5.

19. Galie N, Humbert M, Vachiery JL, Gibbs S, Lang I, Torbicki A, et al. 2015 ESC/ ERS guidelines for the diagnosis and treatment of pulmonary hypertension: the joint task force for the diagnosis and treatment of pulmonary hypertension of the European Society of Cardiology (ESC) and the European Respiratory Society (ERS): endorsed by: Association for European Paediatric and Congenital Cardiology (AEPC), International Society for Heart and Lung Transplantation (ISHLT). Eur Heart J. 2016:37(1):67-119.

20. Galie N, Beghetti M, Gatzoulis MA, Granton J, Berger RM, Lauer A, et al. Bosentan therapy in patients with Eisenmenger syndrome: a multicenter, double-blind, randomized, placebo-controlled study. Circulation. 2006; 114(1):48-54.

21. Channick RN, Simonneau G, Sitbon O, Robbins IM, Frost A, Tapson VF, et al. Effects of the dual endothelin-receptor antagonist bosentan in patients with pulmonary hypertension: a randomised placebo-controlled study. Lancet. 2001;358(9288):1119-23.

22. Iglarz M, Landskroner K, Bauer Y, Vercauteren M, Rey M, Renault B, et al. Comparison of Macitentan and Bosentan on right ventricular remodeling in a rat model of non-vasoreactive pulmonary hypertension. J Cardiovasc Pharmacol. 2015;66(5):457-67.

23. Clozel M. Endothelin research and the discovery of macitentan for the treatment of pulmonary arterial hypertension. Am J Physiol Regulatory Integr Comp Physiology. 2016;311(4):R721-R6.

24. Iglarz M, Binkert C, Morrison K, Fischli W, Gatfield J, Treiber A, et al. Pharmacology of macitentan, an orally active tissue-targeting dual endothelin receptor antagonist. J Pharmacol Exp Ther. 2008;327(3):736-45.

25. Pulido T, Adzerikho I, Channick RN, Delcroix M, Galie N, Ghofrani HA, et al. Macitentan and morbidity and mortality in pulmonary arterial hypertension. N Engl J Med. 2013;369(9):809-18.

26. Jansa P, Pulido T. Macitentan in pulmonary arterial hypertension: a focus on combination therapy in the SERAPHIN trial. Am J Cardiovasc Drugs. 2018; 18(1):1-11. 
27. Gatzoulis MA, Landzberg M, Beghetti M, Berger RM, Efficace M, Gesang S, et al. Evaluation of Macitentan in patients with Eisenmenger syndrome. Circulation. 2019;139(1):51-63.

28. Blok IM, van Riel AC, van Dijk AP, Mulder BJ, Bouma BJ. From bosentan to macitentan for pulmonary arterial hypertension and adult congenital heart disease: further improvement? Int J Cardiol. 2017;227:51-2.

29. Herbert S, Gin-Sing W, Howard L, Tulloh RMR. Early experience of Macitentan for pulmonary arterial hypertension in adult congenital heart disease. Heart Lung Circ. 2017;26(10):1113-6.

30. Sitbon O, Cottin V, Canuet M, Clerson P, Gressin V, Perchenet L, et al. Initial combination therapy of macitentan and tadalafil in pulmonary arterial hypertension. Eur Respir J. 2020;56:3.

31. Galie N, Manes A, Branzi A. Prostanoids for pulmonary arterial hypertension. Am J Respir Med. 2003;2(2):123-37.

32. Rosenzweig EB, Kerstein D, Barst RJ. Long-term prostacyclin for pulmonary hypertension with associated congenital heart defects. Circulation. 1999; 99(14):1858-65.

33. Fernandes SM, Newburger JW, Lang P, Pearson DD, Feinstein JA, Gauvreau $\mathrm{K}$, et al. Usefulness of epoprostenol therapy in the severely ill adolescent/ adult with Eisenmenger physiology. Am J Cardiol. 2003;91(5):632-5.

34. Thomas IC, Glassner-Kolmin C, Gomberg-Maitland M. Long-term effects of continuous prostacyclin therapy in adults with pulmonary hypertension associated with congenital heart disease. Int J Cardiol. 2013;168(4):4117-21.

35. Hoeper MM, Olschewski H, Ghofrani HA, Wilkens H, Winkler J, Borst MM, et al. A comparison of the acute hemodynamic effects of inhaled nitric oxide and aerosolized iloprost in primary pulmonary hypertension. German PPH study group. J Am Coll Cardiol. 2000;35(1):176-82.

36. Yang SI, Chung WJ, Jung SH, Choi DY. Effects of inhaled iloprost on congenital heart disease with Eisenmenger syndrome. Pediatr Cardiol. 2012; 33(5):744-8.

37. Cha KS, Cho KI, Seo JS, Choi JH, Park YH, Yang DH, et al. Effects of inhaled iloprost on exercise capacity, quality of life, and cardiac function in patients with pulmonary arterial hypertension secondary to congenital heart disease (the Eisenmenger syndrome) (from the EIGER study). Am J Cardiol. 2013; 112(11):1834-9.

38. Chon MK, Cho Kl, Cha KS, Seo JS, Kim DS. Effects of long-term iloprost treatment on right ventricular function in patients with Eisenmenger syndrome. J Cardiol. 2017;69(5):741-6.

39. Condliffe R, Clift P, Dimopoulos K, Tulloh RMR. Management dilemmas in pulmonary arterial hypertension associated with congenital heart disease. Pulm Circ. 2018;8(3):2045894018792501

40. Zuckerman WA, Leaderer D, Rowan CA, Mituniewicz JD, Rosenzweig EB. Ambrisentan for pulmonary arterial hypertension due to congenital heart disease. Am J Cardiol. 2011;107(9):1381-5.

41. Galie N, Jansa P, Pulido T, Channick RN, Delcroix M, Ghofrani HA, et al. SERA PHIN haemodynamic substudy: the effect of the dual endothelin receptor antagonist macitentan on haemodynamic parameters and NT-proBNP levels and their association with disease progression in patients with pulmonary arterial hypertension. Eur Heart J. 2017:38(15):1147-55.

42. Chau EM, Fan KY, Chow WH. Effects of chronic sildenafil in patients with Eisenmenger syndrome versus idiopathic pulmonary arterial hypertension. Int J Cardiol. 2006

43. Thomas IC, Glassner-Kolmin C, Gomberg-Maitland M. Long-term effects of continuous prostacyclin therapy in adults with pulmonary hypertension associated with congenital heart disease. Int J Cardiol. 2013.

44. Skoro-Sajer N, Gerges C, Balint OH, Kohalmi D, Kaldararova M, Simkova I, et al. Subcutaneous treprostinil in congenital heart disease-related pulmonary arterial hypertension. Heart. 2018;104(14):1195-9.

45. Iversen K, Jensen AS, Jensen TV, Vejlstrup NG, Sondergaard L. Combination therapy with bosentan and sildenafil in Eisenmenger syndrome: a randomized, placebo-controlled, double-blinded trial. Eur Heart J. 2010;31(9): 1124-31.

46. D'Alto M, Romeo E, Argiento P, Sarubbi B, Santoro G, Grimaldi N, et al. Bosentan-sildenafil association in patients with congenital heart diseaserelated pulmonary arterial hypertension and Eisenmenger physiology. Int J Cardiol. 2012;155(3):378-82.

47. El-Kersh K, Suliman S, Smith JS. Selexipag in congenital heart diseaseassociated pulmonary arterial hypertension and Eisenmenger syndrome: first report. Am J Ther. 2018;25(6):e714-e5.

48. Coghlan JG, Channick R, Chin K, Di Scala L, Galie N, Ghofrani HA, et al. Targeting the prostacyclin pathway with Selexipag in patients with pulmonary arterial hypertension receiving double combination therapy: insights from the randomized controlled GRIPHON study. Am J Cardiovasc Drugs. 2018;18(1):37-47.

49. Sitbon O, Channick R, Chin KM, Frey A, Gaine S, Galie N, et al. Selexipag for the treatment of pulmonary arterial hypertension. N Engl J Med. 2015; 373(26):2522-33.

50. Beghetti M, Channick RN, Chin KM, Di Scala L, Gaine S, Ghofrani HA, et al. Selexipag treatment for pulmonary arterial hypertension associated with congenital heart disease after defect correction: insights from the randomised controlled GRIPHON study. Eur J Heart Fail. 2019;21(3):352-9.

51. Galie N, Humbert M, Vachiery JL, Gibbs S, Lang I, Torbicki A, et al. 2015 ESC/ ERS guidelines for the diagnosis and treatment of pulmonary hypertension: the joint task force for the diagnosis and treatment of pulmonary hypertension of the European Society of Cardiology (ESC) and the European Respiratory Society (ERS): endorsed by: Association for European Paediatric and Congenital Cardiology (AEPC), International Society for Heart and Lung Transplantation (ISHLT). Eur Respir J. 2015.

52. Moceri P, Dimopoulos K, Liodakis E, Germanakis I, Kempny A, Diller GP, et al. Echocardiographic predictors of outcome in eisenmenger syndrome. Circulation. 2012;126(12):1461-8.

53. Diller GP, Alonso-Gonzalez R, Dimopoulos K, Alvarez-Barredo M, Koo C, Kempny A, et al. Disease targeting therapies in patients with Eisenmenger syndrome: response to treatment and long-term efficiency 2013;167(3):840-847.

54. Dimopoulos K, Inuzuka R, Goletto S, Giannakoulas G, Swan L, Wort SJ, et al. Improved survival among patients with Eisenmenger syndrome receiving advanced therapy for pulmonary arterial hypertension. Circulation. 2010; 121(1):20-5.

55. Dimopoulos K, Diller GP, Opotowsky AR, D'Alto M, Gu H, Giannakoulas G, et al. Definition and Management of Segmental Pulmonary Hypertension. J Am Heart Assoc. 2018;7:14.

56. Diaz-Caraballo E, Gonzalez-Garcia AE, Renones M, Sanchez-Recalde A, Garcia-Rio F, Oliver-Ruiz JM. Long-term bosentan treatment of complex congenital heart disease and Eisenmenger's syndrome. Rev Esp Cardiol. 2009;62(9):1046-9

57. Baptista R, Castro G, da Silva AM, Monteiro P, Providencia LA. Long-term effect of bosentan in pulmonary hypertension associated with complex congenital heart disease. Rev Port Cardiol. 2013:32(2):123-9.

58. Schuuring MJ, Bouma BJ, Cordina R, Gatzoulis MA, Budts W, Mullen MP, et al. Treatment of segmental pulmonary artery hypertension in adults with congenital heart disease. Int J Cardiol. 2013;164(1):106-10.

59. Yamamura K, Nagata H, Ikeda K, Ihara K, Hara T. Efficacy of bosentan therapy for segmental pulmonary artery hypertension due to major aortopulmonary collateral arteries in children. Int J Cardiol. 2012;161(1):e1-3.

60. Diller GP, Kempny A, Inuzuka R, Radke R, Wort SJ, Baumgartner $\mathrm{H}$, et al. Survival prospects of treatment naive patients with Eisenmenger: a systematic review of the literature and report of own experience. Heart. 2014;100(17):1366-72.

61. Baumgartner H, De Backer J, Babu-Narayan SV, Budts W, Chessa M, Diller GP, et al. ESC guidelines for the management of adult congenital heart disease. Eur Heart J. 2020;2020.

62. Lopes AA, O'Leary PW. Measurement, interpretation and use of haemodynamic parameters in pulmonary hypertension associated with congenital cardiac disease. Cardiol Young. 2009;19(5):431-5.

63. Manes A, Palazzini M, Leci E, Bacchi Reggiani ML, Branzi A, Galie N. Current era survival of patients with pulmonary arterial hypertension associated with congenital heart disease: a comparison between clinical subgroups. Eur Heart J. 2014:35(11):716-24.

\section{Publisher's Note}

Springer Nature remains neutral with regard to jurisdictional claims in published maps and institutional affiliations. 